\title{
Formas de salir de casa, o cómo escapar del Ogro: relatos de filiación en la literatura chilena reciente*
}

\author{
Lorena Amaro Castro**
}

\begin{abstract}
Resumen
Durante la última década se observa en el Cono Sur una ingente producción, testimoniante y ficcional, literaria y cinematográfica, de relatos que abordan la experiencia infantil desde una perspectiva política o bien, en sentido inverso, la experiencia política desde una perspectiva infantil, para contar los años de dictadura. La reciente narrativa chilena se aproxima al tema desde posiciones que no se vinculan directamente con la violación de los derechos humanos o el trauma, pero que resultan tocadas por lo que el crítico Jaime Hagel llamó en los ochenta "la era del Ogro". En este artículo analizaré cómo se imbrican filiación y ciudadanía, memoria y enunciación, proponiendo una lectura de narrativas en que el niño viaja y ocupa, literal y epistémicamente, el lugar "de asiento trasero" del auto.
\end{abstract}

Palabras clave: Relatos de filiación, dictadura chilena, infancia.

\section{Ways of leaving home or how to escape the Ogre: filiation stories in recent Chilean literature}

\begin{abstract}
During the last decade in the Southern Cone, a vast production of fictional and testimonial literature and film has been produced with stories that address childhood in two different perspectives: either the political experience of childhood, or conversely, the political experience from a child's perspective, as a means to recount the years of dictatorship. Recent Chilean narrative approaches the subject from positions that are not linked directly to the violation of human rights or trauma, but which are touched by what the critic Jaime Hagel called in the eighties, "the era of the ogre". This article will analyze the interweavings between filiation and citizenship, and memory and enunciation, thus proposing a reading of narratives in which the child travels taking, both literally and epistemically, the back seat of the car.
\end{abstract}

Key words: Filiation literature, Chilean dictatorship, childhood.

Recibido: 27-07-2013 Aceptado: 06-08-2013

* El siguiente artículo es parte de un proyecto de libro, financiado primero por el Concurso de Creación y Cultura Artística de la Pontificia Universidad Católica de Chile (2012) con el título "Infancias: Representaciones de inocencia y experiencia en la narrativa chilena del siglo XX/XXI" y luego por el Fondo del Libro -Fomento de la Creación 2013- Profesional Ensayo, N ${ }^{\circ 5578}$, del Consejo Nacional de la Cultura y las Artes, con el título “En el País de Nunca Jamás: ensayos sobre la infancia en la cultura chilena".

** Chilena, Doctora en Filosofía, Universidad Complutense de Madrid. Profesora Asociada, Instituto de Estética, Pontificia Universidad Católica de Chile, Santiago, Chile, lamaro@uc.cl 
Durante el último lustro se observa en el Cono Sur una ingente producción, testimoniante y ficcional, literaria y cinematográfica, de relatos que, como éste, abordan la experiencia infantil desde una perspectiva política o bien, en sentido inverso, la experiencia política desde una perspectiva infantil. En Argentina, Mariana Enriquez (Los peligros de fumar en la cama), Martín Kohan (Ciencias morales), Selva Almada (Un viento que arrasa), Fabián Casas (Los Lemmings y otros), Hebe Uhart (Relatos reunidos), Patricio Pron (El espiritu de mis padres sigue subiendo en la lluvia); en Uruguay, Inés Bortagaray (Pronto, listos, ya) y Horacio Cavallo (Oso de trapo); en Chile, Alejandro Zambra (Formas de volver a casa), Diego Zúñiga (Camanchaca), Alejandra Costamagna (Animales domésticos), Nona Fernández (Fuenzalida), entre otros, han hecho de los recuerdos de infancia un auténtico locus de la memoria. Se trata, en su mayoría, de relatos definidos como ficcionales, aunque con indudables elementos referenciales (en varios de ellos incluso coinciden el nombre del narrador, el protagonista y el autor). Pero en ellos, más que la figura del niño, la que campea es, realmente, la del hijo. Hijos que recuerdan que fueron niños o que recuerdan cómo eran o cómo no eran sus padres cuando ellos eran niños. En el documental autobiográfico, irrumpen los hijos del trauma político ${ }^{1}$. En el cine de ficción y la literatura, los hijos de otros traumas: sociales, conyugales, económicos. ¿Por qué ahora? Evidentemente, los cuarenta años del Golpe Militar no han pasado en vano: los que eran niños y quienes nacieron un tiempo después, han crecido y escriben². Pero hay más razones.

Desde una perspectiva estética y política es necesario considerar estas narrativas con más amplitud literaria. En 1996, Dominique Viart propuso para una serie de relatos aparecidos en ese país desde los ochenta en adelante, la noción de "récit de filiation", distinguiendo de esta

1 Fuera de la literatura, en el ámbito del cine chileno, se podrían citar muchos otros ejemplos, como los de las películas Hija, de María Paz González (2012), Huacho, de Alejandro Fernández Almendras (2009), De jueves a domingo, de Dominga Sotomayor (2012), entre otros. Pero es quizás en los documentales autobiográficos donde se puede apreciar más nítidamente el viraje de lo político colectivo a una mirada íntima de la experiencia familiar. Pienso que conviene citar aquí al crítico Gonzalo Aguilar en su libro sobre el nuevo cine argentino, cuando plantea que la ausencia del protagonista histórico popular, tan presente en las producciones de los 70 y 80, "llevó al cine a posar su mirada en una agrupación más pequeña pero no menos venerada: la familia" (41), exhibiendo principalmente su descomposición, incluso cuando solo es aludida. En Chile este giro es verificable en los documentales de hijos de militantes, como El edificio de los chilenos, de Macarena Aguiló (2011) y Mi vida con Carlos, de Germán Berger (2009) en que preguntas muy personales -si bien de interés público- atraviesan la búsqueda documental, para no encontrar respuesta.

2 Los autores que abordaré aquí nacieron entre 1970 y 1987 (Alejandra Costamagna, Nona Fernández, Alejandro Zambra y Diego Zúñiga, en orden cronológico). 
manera una nueva forma de narración, que a diferencia de los relatos autobiográficos y autoficcionales en general, se interrogaba ya no sobre el sujeto en sí, sino sobre su herencia ${ }^{3}$. Como si la difusión del psicoanálisis hubiese arruinado de antemano todo proyecto autobiográfico, dice, los escritores abandonan la búsqueda de la totalidad del sujeto, para reemplazar, "l'investigation de leur intériorité par celle de leur antériorité familiale" $(4)^{4}$. El narrador busca conocer y a la vez cuestionar su herencia, enfrentando lo que Viart llama "el silencio de los padres". Por su parte, el crítico Laurent Demanze llama la atención sobre otro aspecto de los relatos de filiación, y es que no sólo van a la caza de la memoria infantil y una herencia familiar, sino que entrañan también interrogantes sobre la herencia literaria, lo que hace la búsqueda doblemente interesante. Este tipo de textos cuestionan, pues, no sólo la autoridad paterna, su verdad y su decir, sino que trascienden esa posibilidad hacia formas de crítica de la herencia social, cultural y política nada desdeñables. Este aspecto del relato de filiación, como veremos, encuentra también un lugar en el corpus chileno.

Hay algunas preguntas que parecen ineludibles al asomarse a este universo literario: ese pasado, esa infancia que relatan, ¿puede ser de algún modo, a la manera romántica, un paraíso perdido? ¿Cómo se retorna al paraíso perdido de la infancia, si en él nos esperan los monstruos o, usando un símil de cuento, "la era del Ogro", como llamó, con dolido humor, el escritor y crítico Jaime Hagel al período de Pinochet? (1992: 87).

Recojo del libro Pronto, listos, ya (2006/2010) de la uruguaya Inés Bortagaray, en que una niña viaja con sus hermanos en el asiento trasero del auto rumbo a un balneario, una imagen que dialoga con estas preguntas, en la medida que es una imagen que se repite en varias de las narraciones chilenas que he mencionado: "Veo entonces la nuca de mi padre. Mi padre, el que conduce el auto. El pelo prematuramente blanco baja con ondas hasta el cuello. La cabeza está apenas ladeada hacia la derecha, en un gesto natural que yo repito. El asiento es erguido.

3 La aplicación del concepto "relato de filiación", pensado para la literatura francesa, a la literatura chilena reciente, es uno de los principales aportes de la tesis doctoral de Sarah Roos, doctoranda de la Universidad de Konstanz con quien sostuve una interesante conversación en 2012. Ella hace explícita esta vinculación en ponencias presentadas en el congreso Sochel (Osorno, noviembre de 2012) y Ceisal (Oporto, 2013). La primera de ellas fue reelaborada como artículo, publicado en revista Aisthesis (v. bibliografía).

4 "La investigación de su interioridad por aquella de su anterioridad familiar". 
Mi padre es erguido. Maneja rápido, pero con cuidado. Yo le tranco el botón de la puerta. Ahora sí, está a salvo" (9). La niña, con su gesto, hace algo más que proteger a su padre. Nos indica que está consciente de un peligro que trasciende su mundo infantil, un peligro que habita en el mundo de los adultos. Si bien en el libro de Bortagaray las alusiones son levísimas, ese mundo es el del clima represivo originado por un régimen dictatorial.

Abordaré textos de Alejandro Zambra, Alejandra Costamagna, Diego Zúñiga y Nona Fernández, en que los niños/hijos se dejan llevar por sus padres en viajes inciertos y por paisajes enrarecidos. ¿Qué papel les cupo representar a esos hijos que acompañaban silenciosos a unos padres que, años más tarde, descubrirían como sujetos frágiles, desvalidos, devorados por su historia y la Historia?

\section{Llenar el blanco agresivo}

En plena década de los 80 Rodrigo Cánovas hablaba de las marcas de la experiencia autoritaria en el lenguaje literario chileno, el que surgía en muchos casos como una reacción a la violencia y que recurría a las elipsis, las metáforas y las ambivalencias para poder narrar, bajo la fórmula que entonces se llamó del "faction", las iniquidades de la dictadura. Otros críticos describían la presencia de un narrador colectivo en esas tramas (Vargas 123), pero eran desmentidos por otros que más bien observaban la aparición de un yo con voz dictatorial: "este narrador-dictador dice y hace el mundo, encarnando un yo autoritario que prohíbe la expresión de otros múltiples yoes que volverían inestable su pretensión de identidad" (Muñoz 61).

Hoy sería difícil captar, en un artículo que busque dar cuenta de la creciente producción narrativa recogida en editoriales trasnacionales e independientes, las tonalidades de una sola voz: las hay muy diversas. En oposición a la sedimentación de formas "tradicionales" o hegemónicas, se experimenta con formas autoficcionales y autobiográficas, provocando torsiones dentro del realismo a las que contribuye la introducción de la perspectiva infantil. Este tipo de foco narrativo propende a la desestabilización de los relatos, los vuelve precarios y parciales, aunque en su fragmentariedad constituye igualmente un aporte a la reconstrucción de nuestra memoria elidida, ese "blanco agresivo" que Diamela Eltit describía a 30 años del Golpe (102) y que tras diecisiete años de dictadura 
y veintitrés de gobiernos que pactaron el silencio y asumieron, en los hechos, las consignas neoliberales, es colmado por imágenes que en su superficie siguen birlando lo fundamental del drama político chileno, el proyecto que alguna vez pudo hacer del país algo distinto del laboratorio social, mercantil, en que se ha convertido hoy.

Recogiendo y ahondando en ese contexto sociopolítico, Rubí Carreño ha hecho un corte en la situación narrativa actual, en su libro Memorias del nuevo siglo: jóvenes, trabajadores y artistas en la novela chilena reciente (2009). El asunto que subraya ese título es, lo sabemos como sociedad, ineludible: la construcción, a través de un largo proceso que siempre se reinicia para no cristalizar jamás en una verdad única, de la memoria colectiva. Carreño propone una tipología, en que incluye las memorias de artistas, de trabajadores y, más cerca de esta reflexión, las "novelas de memorias juveniles", las que a través de diversos formatos explorarían los últimos treinta años de la historia chilena: "El golpe y la dictadura se narran desde una percepción infantil o juvenil -escribe Carreño-. Esto influye en que los hechos se interpretan de manera incompleta o diferente a las explicaciones de los adultos. Desde esta perspectiva, el discurso sobre la familia y los amigos tenderá a ser más importante que el discurso político..." (24). Complementando el discurso de Carreño, se podría agregar una cuarta forma de la memoria, discernible, en realidad, de la memoria juvenil: la de los hijos/niños, cuya interpretación de los hechos proviene del escudriñamiento de los silencios familiares y una profunda soledad cotidiana.

El crítico Ignacio Álvarez también analiza en un corpus reciente: el mosaico de la memoria dictatorial ${ }^{5}$. Intenta una clasificación vinculada con la alegorización de la nación y llama "alegorías de la temporalidad" a aquellos textos que "representan un intento productivo por influir en las políticas de la memoria. Lejos de la amnesia que tanto se ha criticado en el manejo político de la postdictadura, los textos que pertenecen a esta modalidad reaccionan de un modo creativo al imperativo de la verdad, esto es, la verdad que ha sido esquiva para las víctimas y la que intentan

5 Ignacio Álvarez hace una excelente síntesis de diversos planteamientos críticos en torno a los nuevos narradores: recoge los textos de Rubí Carreño y también aquellos de Cédomil Goic, Rodrigo Cánovas, Leonidas Morales, Luis Cárcamo Huechante e Idelber Avelar (2012a), además de ofrecer una nueva mirada sobre la cuestión de las alegorías de la nación en los países del "Tercer Mundo" y sus producciones literarias. En otro artículo (2012b), plantea una nueva clasificación, basada en la relación de los narradores con la experiencia del mundo material, recurriendo a categorías filosóficas clásicas ("epicúreos", "escépticos" y "estoicos" ). 
imponer los victimarios" (28). La noción de "relato de filiación" es, por cierto, adosable a esta categoría.

\section{Hijo(a)s herido(a)s}

En Formas de volver a casa, de Alejandro Zambra (2011), un escritor procura crear una novela sobre un profesor/escritor que se reencuentra con su pasado a través de una mujer, de la cual estuvo enamorado en su infancia y quien da la clave política de esta historia. Tanto en uno como en otro nivel narrativo hay un hijo que juzga la cobarde posición de los padres de clase media ante la dictadura, habitantes de un barrio sin historia en los márgenes de la capital. En Camanchaca, de Diego Zúñiga (2009), un hijo viaja con su padre desde Iquique a Tacna para tratarse los dientes, uno de los muchos viajes narrados en la novela, que dan cuenta de la imposibilidad de dialogar que hay entre estas dos generaciones y de un entorno enrarecido por la presencia del desierto y las huellas de la dictadura. En el cuento "Nunca nadie se acostumbra", de Alejandra Costamagna, incluido en el volumen Animales domésticos (2011), el foco narrativo está en una niña de doce años, alejada de su madre, quien viaja junto a su padre a Argentina y al mismo tiempo, al umbral de una nueva conciencia, en que la historia política, contada en sordina, conduce a un drama familiar y un desenlace violento. En la novela Fuenzalida, de Nona Fernández (2012) la narradora, guionista de "culebrones", se encuentra con una foto de su padre en la basura, frente a su casa, hallazgo que la descoloca. Su hijo cae enfermo y ambas situaciones dan pie a un relato sobre aquel padre ausente y casi olvidado, que combina géneros como las películas de artes marciales y el drama televisivo, pero con un trasfondo dictatorial.

En este corpus se teje una crítica mirada del mundo de los adultos, en relatos que además presentan algunos rasgos autobiográficos, verificables en entrevistas y reportajes. La perspectiva elegida para realizar su crítica y reconstruir la memoria es la del adulto que va a la caza de su infancia o directamente, la mirada limpia del niño o la niña que se enfrenta a un enrarecido mundo adulto.

Andrea Jeftanovic plantea que la incorporación de la perspectiva infantil en los relatos y la dramaturgia contemporáneas "es capaz de hacer algo que en la realidad y en la historia es impensable: que los niños adquieran roles protagónicos y señalen arbitrariedades, denuncien 
injusticias y se rebelen contra el orden impuesto por los mayores" (2012, 11). Estas formas de hacer literatura promoverían a los hijos de actores secundarios a protagonistas, en la línea explorada escrituralmente por los autores aquí abordados.

\section{Una novela "de tesis": Formas de volver a casa}

La novela de Zambra constituye un relato de filiación en el doble sentido propuesto por Demanze, esto es, incorpora la dimensión de la filiación literaria. A través de imágenes como la de Berthe Bovary -hija/personaje secundario por excelencia-, instala la reflexión sobre la filiación más allá de lo que el texto enuncia abiertamente: se advierte cierta voluntad del autor de tender un puente teórico-crítico con otras narraciones; "filiar" la historia que cuenta a una tradición literaria, en este caso la que se ha erigido en Europa a consecuencia de las guerras y las políticas de los campos de exterminio, en que las narraciones postraumáticas interrogan el enigma de los padres, ya sean ellos víctimas o victimarios. Zambra alude a autores como Natalia Ginzburg, autora de un relato autobiográfico indispensable, Léxico familiar o, de forma más velada, Georges Perec. Dice uno de los narradores de Formas...: "Siempre pensé que no tenía verdaderos recuerdos de infancia. Que mi historia cabía en unas pocas líneas. En una página, tal vez. Y en letra grande. Ya no pienso eso" (83). La frase es muy similar a uno de los primeros enunciados de W o el recuerdo de la infancia (1974), en que Perec, hijo de un soldado muerto en el frente durante la Segunda Guerra Mundial y una madre desaparecida en Auschwitz, prefirió, para hablar de la historia de sus padres, la ambigüedad, la indeterminación, los juegos escriturales ${ }^{6}$. "No tengo recuerdos de infancia", afirmaba.

En Formas devolver a casa es posible recuperar la memoria, y a diferencia de lo que ocurre con el niño Gaspard Winckler, de $W$, retornar a casa. El proceso es vivido por alguien que no ha experimentado directamente un trauma, alguien en cuya familia "no había muertos ni había libros", marca no sólo política, también social. Decide entonces contar la historia de Claudia: "Sabía poco, pero al menos sabía eso: que nadie habla por los demás. Que aunque queramos contar historias ajenas terminamos

6 La similitud entre ambas frases fue advertida por Viviana Ruiz en su seminario de grado (2012), sobre la novela de Zambra. 
siempre contando la historia propia" (105). En los relatos de filiación descritos por Viart la búsqueda del sujeto dice relación con la herencia de los padres y ellos ofrecen generalmente un secreto, un enigma, un silencio. Aparecen en una foto que es interrogada, observan mudos desde el pasado a sus incómodos retoños, son elididos en las conversaciones, viven en el presente o en la memoria básicamente como enigmas. En la novela de Zambra es el papá de Claudia, amiga del protagonista, quien está bajo la vigilancia de los niños, es él quien guarda un misterio que es resuelto al final. En ese camino de búsqueda, que involucra la memoria, aparecen los padres del protagonista y también los del narrador de esa historia. Se recobran recuerdos aparentemente perdidos.

El tema de la filiación se elabora también en los pasajes referentes al nombre propio, que son varios en esta novela. En Chile, como constata uno de sus narradores, el nombre comporta una marca e incluso un estigma social: el apellido del padre, en un país de huachos, es un significante crucial. Es congruente con las reflexiones sobre la relación entre los nombres y el arribismo y el clasismo chilenos, que el escritor de la novela se dé cuenta de que los personajes de su historia no tienen apellido y diga: "Es un alivio" (53).

Zambra escribe sobre cierta clase media que, promovida intelectualmente y con más cultura y herramientas que sus padres ${ }^{7}$, se enfrenta a su pasado con una mirada distanciada, buscando pistas que ayuden a precisar el presente pero incluso en los casos más duros, enjuiciándolos como en sordina y sin llegar, a diferencia de lo que ocurre con varias narraciones argentinas contemporáneas, a escenas de filicidio o parricidio, como remarca Elsa Drucaroff en su reciente estudio Prisioneros en la torre. Por el contrario, cierta mansedumbre caracteriza a los hijos chilenos. Ella se expresa en el gesto de subir al auto, en compañía de sus padres y... dejarse llevar. Se trata de una imagen que se repite y que resulta por ello interesante. Ocurre también en la novela de Zambra: un niño se deja llevar por los padres en el asiento trasero del auto. En el caso de Formas... el protagonista infantil borra sin querer el estribillo de una canción de Raphael del cassette de su madre. Cuando colocan la música en el auto, durante un paseo familiar, él se desgañita cantando el estribillo, para que no adviertan la ausencia de acompañamiento.

7 Rubí Carreño ha analizado este aspecto en Av. Independencia (2013), vinculando en su reflexión las novelas de Zambra y Zúñiga. 
Finalmente, al llegar a casa entierra el cassette y es descubierto en ese momento. Esta historia, no exenta de humor, dice relación con el carácter de impostador del narrador, quien en la novela se apropia de una historia que no es la suya (la de Claudia). El niño canta sin música: no hay hechos ni contextos que respalden su voz. Se encuentra, además, en el asiento de atrás, con una perspectiva sesgada del camino. Una imagen de los hijos bajo el período dictatorial, hijos que se dejaban llevar por sus padres por un mundo pequeño, estrecho. No en vano la novela cierra con esta evocación:

Después del Peugeot 404 mi padre tuvo un 504 azul pálido y luego un 505 plateado. Ninguno de esos modelos circula ahora por la avenida.

Miro los autos, cuento los autos. Me parece abrumador pensar que en los asientos traseros van niños durmiendo, y que cada uno de esos niños recordará, alguna vez, el antiguo auto en que hace años viajaba con sus padres. (164)

El adjetivo "abrumador" sintetiza en gran medida la relación de los dos narradores de la novela con las figuras parentales. Por otra parte, con esta reflexión Zambra parece hacer un guiño a la novela Camanchaca, publicada dos años antes que la suya y que empieza, como se verá más adelante, con un párrafo muy similar. En estos intertextos veo una deliberada construcción del autor, quien teje una especie de red cómplice, una red de hijos desacomodados, a-filiados. Así, por ejemplo, los "cameos" de escritores como Alejandra Costamagna (autora de varias novelas sobre hijos y padres ${ }^{8}$ ), Rodrigo Olavarría (del que cuenta una anécdota de infancia, vinculada con los padres) y el propio Zúñiga.

\section{La lectura política del relato de filiación: Camanchaca}

Camanchaca transcurre principalmente entre viajes, sobre todo a través del desierto. Aquí, los primeros párrafos:

El primer auto que tuvo mi papá fue un Ford Fairlane, del año 1971, que le regaló mi abuelo cuando cumplió los quince años.

8 Costamagna aborda la experiencia infantil, la violencia dictatorial, la orfandad y la recuperación de la memoria en textos como En voz baja (1996), Cansado ya del sol (2002), Dile que no estoy (2007) y el reciente Había una vez un pájaro (2013). Me he referido anteriormente a estos relatos de Costamagna en dos reseñas literarias (V. bibliografía). 
El segundo fue un Honda Accord, del año 1985, color plomo.

El tercero fue un BMW 850i, azul marino, del año 1990, con el que mató a mi tío Neno.

El cuarto es una camioneta Ford Ranger, color humo, en la que vamos atravesando el desierto de Atacama. (7)

Este hijo, de veinte años, se comporta aún como un niño: sin autonomía, se sube al auto para que su padre conduzca y sostenga a lo largo del trayecto un discurso vacío y estúpido: "Yo subo a su camioneta, me pongo los audífonos, enciendo el pendrive y voy con él" (8). Su conducta es la de un autómata. Se trata de un personaje despojado de historia, al que su madre agobia con murmuraciones y versiones inciertas del pasado y el padre no ofrece absolutamente nada, sólo el adelgazamiento de una realidad cada vez más precaria, en el horizonte cubierto por la camanchaca. Esta conducta idiotizada, sin embargo, esconde el silencioso anhelo del personaje de desvelar los misterios que lo rondan y sobre los cuales él también procura no hablar. Los secretos son varios: la muerte del tío Neno, la relación incestuosa y traumática del protagonista con su madre. El destino de su prima, hija del tío Neno, el pasado de su madrastra, las desapariciones que son evocadas en la pensión del abuelo, todas heridas que el protagonista parece entender en su devastación, pero sobre las cuales no logra articular un discurso.

El personaje, sin embargo, no parece un idiota ni un psicótico: la suya es una condición política. No es extraño que en Italia, país que conoce las narrativas de filiación y los traumas que las originan, esta novela, que transcurre en un mundo de referencias muy recientes, haya sido leída como una novela de postdictadura. El crítico Dario De Cristofaro escribe, aludiendo al título Camanchaca, que la niebla a la que alude la novela esconde la realidad, como lo hace el propio régimen político, que oculta la violencia impune de la dictadura. Él establece la relación entre el misterio familiar -quizás no más grande o más tremendo que otrosy la falta de verdad que atañe a toda una comunidad, convirtiendo de este modo a la novela, muy breve y fragmentaria, en una alegoría de la memoria, el ocultamiento y el silencio en Chile.

Camanchaca, a diferencia de otras narrativas de hijos, se cierra en su no decir, y termina tan enigmáticamente como comienza, con el hijo de copiloto del padre, imposibilitado de ver realmente, en un escenario 
imaginario en que habitan los muertos, todos: los muertos familiares, los muertos de la comunidad:

Durante el viaje no volvemos a hablar. Es tarde. Cruzamos el desierto entre sombras y neblina. Me acerco a la ventana. Veo mi reflejo. Veo a mi papá. Intento observar las estrellas. Pero no se ve nada. Es la camanchaca, dice mi papá. Yo lo observo de reojo. Él conduce a ciento cuarenta kilómetros por hora. Cierro los ojos. Y los veo en la carretera, ahí, tendidos (...) Los cuerpos. Niños y viejos. En mitad de la carretera. Los veo en la mitad del desierto, y mi papá los esquiva, acelera y los esquiva. (115)

En Camanchaca el niño aparece como un sujeto desarraigado de lo político, figura que se encuentra "fuera" y cuestionadora de todas las categorías políticas al uso, como plantea, en sus reflexiones sobre lo "impolítico", el filósofo Roberto Espósito. Es interesante, de hecho, que en el párrafo citado sean los cuerpos de niños y viejos los que aparecen sembrados en la carretera, llevados a un plano fantástico en que el padre, lejos de horrorizarse, prosigue su camino arrollador. Autos, compras, películas de acción: el mundo del padre, que debiera ser el de la madurez y el ejercicio de la ciudadanía se inscribe con facilidad en las lógicas del mercado, dejando un reguero de cadáveres, cadáveres viejos y nuevos. El niño contempla, con una mirada imposible para el adulto, la reverberación de sus cuerpos en la carretera. El niño es aquí el sujeto antes del sujeto, antes del lenguaje, "una experiencia muda en el sentido literal del término", escribe Agamben. Sólo registra, impávido, lo que ve. Los cuerpos de niños y viejos que observa no son más que los desechos, los cuerpos no-útiles, los desangrados por un sistema de mercado en que niños y viejos son "sujetos 'menores' [que] sirven de metáfora del cuerpo como plataforma de poder y del abuso, de la inherente pulsión de dominación y aniquilación, de la necesidad de un chivo expiatorio en el que satisfacer la violencia..." (Jeftanovic et al. 11).

\section{Infancia y bestialidad}

Menos soterrada que en las novelas de Zúñiga o Zambra, esa violencia aparece también como una experiencia decisiva en el cuento de Alejandra Costamagna "Nadie nunca se acostumbra", con que cierra el volumen Animales domésticos. En este libro, la disgregación familiar es el hilo conductor y el título, irónico, no hace más que señalar 
a los "animales" / humanos que habitan en casa, animales que pueden ser bestiales e irreductibles a lo político y lo normativo. Mientras la domesticidad sugiere una vida acomodada a las normas familiares o en la lógica del rebaño, supeditado a una figura de autoridad, jerárquica y ordenadora — su pastor-, el libro nos ubica, irónicamente, de frente a una zooliteratura de las manadas, en que las familias se dispersan y los seres devienen animales o humanos por causa de la enfermedad, el deseo, la muerte. Aquí. En Japón. En un pueblo argentino.

El cuento, que dialoga bastante con otras historias de carretera, como la ya aludida de Inés Bortagaray y, en Chile, con la película De jueves a domingo, estrenada por la joven realizadora Dominga Sotomayor el 2012, refiere el largo viaje desde Chile hacia un pueblo argentino, viaje protagonizado por una niña de doce años -llamada "Jani", diminutivo que evoca el nombre de la autora- y su padre: “... Jani se despide de la perra, dame la patita, y sube con su padre a la citroneta. Por primera vez viajan juntos, solos" (129).

Su posición, pese a ser la única acompañante en el largo periplo, es la del asiento trasero, pero ella la ocupa estableciendo curiosas asociaciones, que hablan del desamparo emocional y la complejidad de las relaciones al interior de esta familia. La niña sufre el abandono de su madre y su padre le prohíbe mencionarla en Argentina: "Y Jani no menciona a su madre, pero la recuerda" (ibíd.). Por otra parte enfrenta la relación amorosa entre el padre y la cuñada (su tía Bettina) y la presencia de la "bebita"; su prima y, como se revela en el momento más violento del relato, su hermana. Como en otros de estos textos, la narración en tercera persona se focaliza en el registro estrecho pero expresivo de una subjetividad infantil, en vilo frente a los conflictos de los padres e incluso despunta, en la intrincada trama familiar, la idea del incesto:

Demasiadas horas adentro de la citroneta blanca con sánguches de queso y salame, agua en una cantimplora y unas ventanas chicas pero suficientes para ver cómo las nubes se ponen gordas y arenosas mientras se alejan de Chile. El padre ha acomodado varios cojines en el suelo del asiento trasero para armar una especie de cama matrimonial, y ahí va Jani. Imagina que va de luna de miel. Pero, ¿con quién? (129 - 130).

De este viaje forzado la distrae el juego de contar los perros que se atraviesan en su camino, juego que inició al recibir el regalo de una perra 
(Daisy) de parte de su madre. La misteriosa ausencia de ellos a su ingreso en el pueblo de Campana -donde recogerán a Bettina y la bebita para viajar a la playa- es el siniestro preludio del desenlace, en que la niña verá destrozado su escuálido mundo, lo que resta del hogar y la infancia.

Hay un calor pesado esa mañana en Campana (...) El padre sale a hacer los últimos trámites al centro. Lleva la citroneta para que le revisen el agua, el aceite, los neumáticos (..) Jani se sube al naranjo dispuesta a perder ahí las horas que restan. ¿Y si los dejara de contar de una vez? Cuatrocientos setenta y siete, habría que corregir, porque el anterior fue un perro dormido. ¿Los que duermen cuentan? Un perro que sueña que es un hombre y despierta aullando debajo de un árbol. Un perro como cualquiera de estos siete que ahora vuelven a aparecer en patota y van con su caminar rumbero buscando restos de basura o quizás qué. A los de ayer se suma el quiltro de la esquina y uno de color hueso, enorme, y otro y otro. Jani no lo puede creer. Retoma el conteo con entusiasmo, casi con furor: cuatrocientos setenta y ocho, cuatrocientos setenta y nueve, cuatrocientos ochenta. Le da un poco de miedo, pero desde la copa del árbol no pasa nada, los perros no trepan. Puede que sueñen que son hombres pero de ahí a trepar... (140)

El asedio de la jauría acabará en el violento ataque de los perros a la tía Bettina. El hecho afectará, más bien liquidará por completo el proyecto familiar del padre, y volcará los deseos de la niña hacia el reencuentro con su madre:

Habrá controles en la carretera y perros con dentaduras aceradas que intentarán reponer las primeras visiones, las más pavorosas de esta mañana, pero habrá tantas palabras por traer a cuento con Milena que Jani se olvidará de los perros, de la tía, de la hermanita, hasta de su viaje de vuelta a Chile sola mientras el padre vela por Bettina en Campana... (142)

La familia es el bestiario privilegiado por Costamagna, un bestiario maldito, ya que en estos personajes "el regreso a casa" -en el sentido que se le puede conferir a un retorno al hogar, sus relaciones de afecto, en suma, a la filiación dulcificada- es prácticamente imposible. La familia es, en realidad, una fuerza violenta que arrasa con la infancia indomesticada. 


\section{Padre país}

Los padres de los tres relatos anteriores son puestos en juicio desde la perspectiva infantil. En Formas de volver a casa la crítica es explícita: ¿por qué esos padres de clase media, que habitaron barrios "sin historia, del Chile de Pinochet" (67) pudieron vivir bajo dictadura sin quedar heridos? Siempre cabe la posibilidad de preguntarse si hubo la posibilidad de tomar otras decisiones, pero en este relato el juicio es más bien demoledor: "Los padres abandonan a los hijos. Los hijos abandonan a los padres. Los padres protegen o desprotegen pero siempre desprotegen..." (73). En Camanchaca, los anhelos de comunicación se ven siempre boicoteados por el padre: "yo quería eso: que una tarde saliéramos y conversáramos. Se lo insinué, pero él no dijo nada. Simplemente se hizo el desentendido" (88). En "Nunca nadie se acostumbra" el padre tampoco ampara a la niña en su angustia: "Se lo va a decir cuando el padre se acerca y le acaricia la cabeza con un gesto que no es cariño y Jani no alcanza a pedirle por favorcito que no abra la boca que empaquen y vuelvan a Chile que ella se va sola a Chile si él no quiere (...) Se lo va a decir pero el padre abre la boca y dice tenemos que hablar. Hay cosas que ya deberías saber, Ja. En la playa vamos a hablar. Jani sospecha que el hombre urde algo. Cada vez que miente la llama Ja" (139). La condena en los textos de estos escritores es evidente; por esto he querido dejar para el final un comentario sobre la sorprendente novela Fuenzalida, de Nona Fernández. A diferencia de los otros textos abordados, aquí el padre aparece principalmente como una fabulación. Si bien el padre "real" de la narradora es un vacío, su apellido, su significante, es el título absoluto de la novela: "Fuenzalida".

La ficción de Nona Fernández propone una modalidad algo distinta de hacer memoria. Lo suyo es un ejemplo de parodia y autoparodia. La narradora, guionista de "culebrones" como lo es la propia autora (ha escrito varias teleseries) imagina una posible historia para el padre que dejó de ver cuando niña. Recurre para ello a elementos de las películas de artes marciales, también de las series dramáticas (el subgénero del drama clínico) para abrirse paso en esta fabulación en que el padre resulta ser un dotado artista marcial que lucha contra los esbirros de la dictadura. En otro extremo textual, la autora incorpora la historia de Sebastián Acevedo, minero del carbón que, exigiendo la liberación de sus dos hijos desaparecidos por la policía secreta, se prendió fuego en 1983, frente a la Catedral de Concepción. La aparición de esta historia resulta un poco 
violenta desde el punto de vista textual: más cercano a las narraciones de los ochenta, opera como una especie de injerto ${ }^{9}$. A través de esta multiplicidad, Fernández construye con destreza el leve equilibrio entre el humor y el horror que caracteriza a esta novela y a su obra de teatro $E l$ taller, estrenada también el 2012.

Hay ciertamente ironía en hacer de ese padre ausente un héroe. La narración deja ver hasta qué punto la figura paterna ha generado una vacancia; “Qué datos manejaba Fuenzalida de mí?”, se pregunta la narradora, fantaseando luego una escena diametralmente opuesta a la del maestro de artes marciales: "Me pregunto dónde habrán ido a parar todas las cabezas de Fuenzalida que mi madre tijereteó de sus fotos. Imagino un grupo grande tirado en el tarro de la basura de su cocina. Muchas caras de Fuenzalida mirándome desde ahí dentro mezcladas con cáscaras de huevo y restos de arroz" (137). Los únicos recuerdos que cree conservar la narradora son los de una infancia temprana, en que la escena del automóvil aparece nuevamente, un recuerdo que "ocurre entre ruedas":

Las ruedas del auto de Fuenzalida, un Renault 5 color ¿verde?, ¿café?, ¿azul? No tengo fotografías de esta escena, pero voy a apostar a que es real (...) Fuenzalida conduce su auto rumbo a la cordillera. Yo estoy a su lado, en el asiento del copiloto, mirando por el parabrisas las líneas blancas e intermitentes estampadas en el cemento. Es el último paseo que hacemos juntos. En unos días más vendrá esa tarde de baldosas sucias en el patio de mi madre y su salida para siempre por la reja de la casa (143).

Durante este paseo la radio anuncia la inmolación de Sebastián Acevedo, noticia que la niña capta apenas, pero que será documentada en otros momentos de la narración. Se trata, ni más ni menos, de un padre que da la vida por sus hijos, modelo heroico, modelo posible para el avatar que constuirá de Fuenzalida: un padre que se enfrenta con valentía a la dictadura, mientras el verdadero padre de la protagonista desaparece sin dejar rastros.

9 Me parece relevante señalar que la novela fue escrita al mismo tiempo que la autora desarrollaba los guiones para "Los archivos del Cardenal", serie televisiva que aborda distintos casos de derechos humanos que sucedieron bajo dictadura. 
"Fuenzalida debe entregar algo, no recuerdo qué, quizá nunca lo supe, a un cliente que vive en el nuevo barrio de La Dehesa. Me lleva para que conozca este sector que se está armando en Santiago. Es importante que lo conozcas, me dice, debes ir a verlo. Yo noto su entusiasmo. La idea de ir juntos a este sitio enigmático y encumbrado le produce felicidad" (144). La cita deja ver un padre real: infantil, ingenuo, como los padres descritos por Zambra, Zúñiga y Costamagna. Pero como resistiéndose a esa imagen, que es la escasa herencia de su huerfanía, la narradora construye un héroe que ese mismo día del paseo, enfrenta en realidad una misión secreta: luchar contra unos agentes de la CNI que han secuestrado a otro hijo, un posible hermanastro de la narradora.

Así va creciendo Fuenzalida, hasta erigirse en religión, en mito, en patria:

Creer en Fuenzalida es un acto de voluntad. Fuenzalida como una opción, una convicción necesaria que hay que sustentar de la misma forma como lo hacen las religiones o los partidos políticos. Con ideas, Con éticas. Con historias. Establecer una mitología Fuenzalida. Una historia fundacional. Inventar una moral, un código de buenas o malas costumbres Una legislación, una señalética, un oráculo, un horóscopo, una brújula, un norte. Fuenzalida como un norte, un sur, un este o un oeste. Fuenzalida como un límite de cualquier tipo. Un mapa que guíe por calles, avenidas, plazas, circunvalaciones, rotondas y comunas de un mismo territorio. Entrar y habitar el enigmático país Fuenzalida. Descubrirlo, fundarlo, construirlo como se construye una buena escena. (165)

La filiación a la que refiere la novela es, curiosamente, "afiliativa". Se adhiere al padre como a una idea o a un conjunto de valores, lo que Edward Said, en El mundo, el texto, el crítico"10, llama "afiliación". El

10 Said se refiere al abandono de las relaciones de "filiación" por las de "afiliación" en los escritores modernistas europeos, en quienes "el fracaso en el impulso creador -el fracaso de la capacidad de producir o procrear hijos- se retrata de tal forma que representa una condición general que aqueja por igual a la cultura y la sociedad" (30). La consecuencia inmediata de las dificultades de la filiación -vista, por cierto, desde los ojos de los "padres" y no de los hijos- es la búsqueda de "nuevas y diferentes formas de concebir las relaciones humanas" (31). El modelo, dice Said, será el de la afiliación horizontal, orden compensatorio, el de las instituciones, los partidos, los clubes, en que acaba por reinstaurarse "la autoridad que en el pasado estaba asociada al orden filiativo" (34). 
producto de esa adhesión es una novela, lazo que reemplaza a los de afecto y protección. Sin embargo, la novela es también la del hijo, Cosme, quien ha caído en un coma y retorna de él. Es por este niño que la narradora construye la historia. Para poder darle una herencia a su hijo, esta vez sí, teñida de afecto, de emoción.

Retratando aquel tiempo oscuro de la dictadura -al que, insisto, es difícil volver como si se tratase de un paraíso perdido, aunque en la televisión los revivals ochenteros estén teñidos de nostalgia fetichistaestos autores conjuran las interrogantes sobre sus orígenes y sobre sí mismos, produciendo una escritura. Allí se apropian de algo que no les perteneció plenamente, sino que les perteneció a "ellos", a los padres.

En esta literatura ha coagulado una herida: se retorna con mirada desencantada de la afiliación partidista y luchadora de los setenta y los ochenta a formas de filiación igualmente poco encantadoras: angustiosas, críticas o casi imposibles. Pero se retorna a ellas: como escribe Zambra, se retorna a casa. Es indudable que hay algo muy conservador en este resguardo familiar, pero, por otra parte, más que estar resguardados, los narradores de estas historias se hallan a la intemperie, interrogándose sobre las esquirlas de la noción de familia introyectada por la dictadura a través de su propaganda ochentera. Se vuelve a casa, pero herido(a).

\section{Conclusiones: salir de casa}

La casa es, desde luego, el lugar privilegiado de la vida privada, y como recuerda Hannah Arendt, el lugar de una privación: la de la esfera pública y la vida política o "verdadera" vida ciudadana, de acuerdo con el pensamiento del mundo clásico, que consideraba menos valioso este espacio, valorizado sobre todo con la modernidad, que santifica el hogar burgués, donde nacen y se cuidan los afectos íntimos. No obstante, siguen existiendo allí las fronteras del poder, en la medida que la casa siguió siendo el espacio de la mujer y los niños, en tanto el varón dominaba la escena pública, lo que nos retrotrae a esa primigenia noción de la casa como lugar de lo no deseado, donde se concentran las actividades relativas apenas a la subsistencia.

Bajo dictadura se podría ver en la casa un lugar de protección. Pero fue también una celda. Se transformó en un lugar de encierro y su umbral, en un límite terrible. Así el microcuento de Pía Barros, "Golpe", en que el paisaje amenazante que se avizora del otro lado de la puerta espejea 
en otras historias que transcurren dentro de las casas, como ocurre por ejemplo en Óxido de Carmen, de Ana María del Río (1986). Salir de casa se volvió peligroso en los ochenta, pero volver a ella, en muchos casos, también.

Si se observa ese trasfondo, parece inevitable pensar que en su novela, Alejandro Zambra utiliza la figura del niño para ir más allá del personaje / individuo que juzga su propia historia y la de sus padres. La novela pareciera decir que en los 80 todos fueron "hijos" de un padre absoluto y tiránico; y que esos hijos/niños de Pinochet se hicieron adultos, pero sin lograr del todo su ciudadanía. Reconstruyendo sus historias, intentan "volver a casa", pero a una casa muy diferente de la real: intentan reconstruirse como una familia/comunidad que ha sido quebrantada. Habría que decir, pues, que la cuestión radica hoy en salir de casa. Pero, ¿a dónde? A tres décadas del golpe militar, Diamela Eltit contrastaba el espacio público colmado de cuerpos y consignas previo al desastre, con el de las calles "normalizadas, recorridas por una prisa distinta" de la postdictadura (104). "La mediocridad que atraviesa el actual pacto político obliga a ejercer un paso productivo y terriblemente personalizado. Los correctos ciudadanos caminan de un lado a otro, impulsados por el cumplimiento imperativo de sus menesteres. Caminan ya completamente domesticados" (104), escribía en el 2003, antes de que la irrupción en el espacio público de los "pingüinos" y estudiantes universitarios el 2006 y el 2011, cuando nuevos cuerpos, como también nuevas consignas y esperanzas ocuparon multitudinariamente la Alameda, exigiendo un sistema educativo más justo y también la reconquista de los espacios perdidos por las privatizaciones y la desmemoria.

Las ficciones a las que me he referido disponen la memoria a modo de recuerdos parciales, escamoteados; epistemes blandas, cerradas: ventanilla del auto, buscando de este modo recuperar aunque sea fragmentos de una experiencia que es también generacional: en las citas de los cuatro autores se recuerda no sólo el viaje junto al padre, sino la marca y el color del auto (o los autos) paternos. Ellos grafican una experiencia generacional de la infancia, experiencia que comienza a tornarse caduca: la de los niños que viven en un mundo de fetiches reconocibles, de marcas escasas, en que aún no gobierna el mundo virtual ni el consumo indiscriminado, un mundo en que los viajes se hacen sin computadores, sin iPods, sin iPads, sin juegos virtuales, sin chats, sin posibilidad alguna de evadirse de la mediocre realidad de los padres, un 
mundo que comienza a desvanecerse en el viaje descrito por Camanchaca. Conjeturo que se trata, pues, de una literatura de despedida que a la vez se resiste a despedirse de esos padres que criticamos. Una literatura de peterpanes dolidos, en difícil tránsito hacia la adultez y la ciudadanía.

\section{Referencias bibliográficas}

Agamben, Giorgio (2003). Infancia e historia. Buenos Aires: Adriana Hidalgo Editora.

Álvarez, Ignacio (2012a). “Tres modalidades de alegoría nacional en las narraciones chilenas del noventa y el dos mil". Taller de Letras 51. 11-31.

- (2012b). "Sujeto y mundo material en la narrativa chilena del noventa y el dos mil: estoicos, escépticos y epicúreos". Revista Chilena de Literatura 82. 7-32.

Amaro, Lorena. "El dolor de la manada", en Revista Intemperie, 2011:http: / / www.revistaintemperie.cl/index. php. / 2011/06/07animales-domesticos-alejandracostamagna/ (Consultado: 20/07/2013).

Arendt, Hannah (2003). La condición humana. Barcelona: Paidós.

Barros, Pía (1986). “Golpe”. En: Miedos transitorios. Santiago de Chile: Ergo Sum.

Bortagaray, Inés (2006). Pronto, listos, ya. Montevideo: Ediciones Artefato.

Cánovas, Rodrigo (1986). Lihn, Zurita, Ictus, Radrigán, Literatura Chilena y Experiencia Autoritaria. Santiago: Salesianos.

Carreño, Rubí (2009). Memorias del nuevo siglo: jóvenes, trabajadores y artistas en la novela chilena reciente. Santiago de Chile: Cuarto Propio.

- (2013). Av. Independencia. Literatura, música e ideas de Chile disidente. Santiago de Chile: Cuarto Propio.

Costamagna, Alejandra (2011). Animales domésticos. Santiago de Chile: Mondadori. 
De Cristofaro, Dario (2012). "Passeremo per il deserto, di Diego Zúñiga". Revista Flaneri. URL:

<http: / / www.flaneri.com/index.php/flaneri / leggi/passeremo_per_il_deserto_di_diego_ zuniga/>. (Consultado: 20/07/2013).

Del Río, Ana María (1986). Óxido de Carmen. Santiago de Chile: Andrés Bello.

Demanze, Laurent (2008). “Récits de filiation”, prólogo al libro Encres orphelines, Pierre Bergounioux, Gérard Macé, Pierre Michon. París: Éditions José Corti.

Drucaroff, Elsa (2011). Los prisioneros de la torre. Política, relatos y jóvenes de la postdictadura. Buenos Aires: Emecé.

Eltit, Diamela (2008). "La memoria pantalla. Acerca de las imágenes públicas como políticas de la desmemoria" (Mayo-Septiembre 2003). Signos vitales. Escrito sobre literatura, arte y politica. Santiago de Chile: Universidad Diego Portales, 101 - 107.

Fernández, Nona (2012). Fuenzalida. Santiago de Chile: Mondadori.

Hagel, Jaime (1992). “Apuntes sobre el cuento". Simpson 7, vol. 1. Santiago. s/r.

Jeftanovic, Andrea; María José Navia, María Belén Pérez y Lucía Sayagués (2011). Hablan los hijos: Discursos y estéticas de la perspectiva infantil en la literatura contemporánea. Santiago de Chile: Cuarto Propio.

Muñoz, Josefina (1994). "Reflexiones acerca de algunas huellas del poder en la narrativa de la generación del ' 80 '. En Berenguer, Carmen et al. Escribir en los bordes. Santiago: Cuarto Propio, 159-166.

Perec, Georges (2005). W o el recuerdo de la infancia. Santiago de Chile: LOM.

Roos, Sarah (2013). "Micro- y macrohistoria en los relatos de filiación chilenos". Aisthesis 54. 335-351. 
----. (2013). "La memoria intergeneracional dialoguizante en el relato de filiación". Ponencia prsentada en el Congreso CEISAL, Oporto.

Ruiz, Viviana (2012). Personajes secundarios: politica y autoficción en Formas de volver a casa, de Alejandro Zambra. Seminario realizado para obtener el grado de Licenciada en Estética, Instituto de Estética, Pontificia Universidad Católica de Chile. Profesora patrocinante: Lorena Amaro.

Vargas, Marcelo (1994). "La narrativa post-golpe ante la crítica. Caracterización del cuento en la generación del '87". Literatura y Lingüística 7. 107-125.

Viart, Dominique (2009). "Le silence des pères au principe du «récit de filiation»". Études françaises 3, Volume 45 (Figures de l'héritier dans le roman contemporain). 95-112.

Zambra, Alejandro (2011). Formas de volver a casa. Barcelona: Anagrama. Zúñiga, Diego (2009). Camanchaca. Santiago de Chile: La Calabaza del Diablo. 
